\title{
Médicos para atenção primária em regiões rurais e remotas no Brasil: situação atual e perspectivas
}

Physicians for primary health care in rural and remote regions in Brazil: current situation and perspectives

Médicos para la atención primaria en regiones rurales y remotas en Brasil: situación actual y perspectivas

Michael Schmidt Duncan. Secretaria Municipal de Saúde do Rio de Janeiro. Rio de Janeiro, RJ, Brasil. msduncan81@gmail.com (Autor correspondente) Leonardo Vieira Targa. Universidade de Caxias do Sul (UCS). Caxias do Sul, RS, Brasil. targalv@gmail.com

Ao longo do último ano, com o Projeto Mais Médicos para o Brasil (PMMB), ganhou força a discussão sobre o provimento de médicos para a atenção primária brasileira. O debate vem sendo acirrado, permeado por discussóes ideológicas, e frequentemente se desviando de uma análise cientificamente embasada dos temas em questão. Um dos poucos pontos consensuais é que a distribuiçáa de médicos nas diferentes regióes do Brasil é muito desigual, ${ }^{1,2}$ contribuindo para o que vem sendo denominado defasagem rural-urbana.

Mesmo enfrentando forte oposição, especialmente das entidades médicas, ${ }^{3}$ o PMMB foi em frente, contando atualmente com mais de 14 mil profissionais, de diferentes nacionalidades, dos quais cerca de 11 mil são cubanos. Esses médicos estão distribuídos em 3,8 mil municípios e 33 distritos de saúde indígena, ${ }^{4}$ todos teoricamente trabalhando na Estratégia Saúde da Família, ou seja, atuando na porta de entrada do sistema de saúde. Esse projeto constitui hoje a principal política pública de provimento de recursos humanos para parcela significativa da população brasileira e é a primeira etapa, atualmente a mais visível, de um programa mais amplo de reformulação da força de trabalho médica no país, denominado Programa Mais Médicos, ${ }^{5}$ a maior parte do qual está em construção.

Embora o alcance dessa iniciativa seja inegável, deve-se destacar a preocupação quanto à sua sustentabilidade a longo prazo, que dependerá do sucesso dos demais componentes do programa e da superação das deficiências do PMMB. Uma das principais deficiências é que esse projeto prevê a contratação do médico por um período de três anos, ${ }^{5}$ sem estarem definidas estratégias claras para sua fixação ou substituição por outro profissional que irá permanecer na mesma comunidade por um tempo maior. Pelo contrário, a partir do momento em que o gestor municipal fica desobrigado ao pagamento dos salários, devendo apenas oferecer uma contrapartida de moradia e alimentação, constrói-se uma grande dependência dos municípios sobre o programa, o que pode ser extremamente destrutivo para o processo de estruturação de sistemas de saúde locais. De fato, tem havido relatos de demissão de médicos para dar lugar a esses médicos novos temporários, ${ }^{6}$ mesmo isso estando contra as regras do programa. ${ }^{5}$.

Por esse motivo, o consenso internacional é de que, paralelamente a estratégias de curto prazo para provimento de profissionais médicos, deveriam ser implementadas medidas de médio e longo prazo, multifacetadas e focadas na retenção dos profissionais. ${ }^{7}$ Deveria-se também investir na construção de um sistema de saúde forte, regionalizado e alicerçado nos atributos da atenção primária: primeiro contato, longitudinalidade, integralidade e coordenação do cuidado. ${ }^{8}$ Os interesses imediatistas de provimento não podem conflitar com a necessidade a longo prazo de fixação de profissionais e de integração destes em um sistema de saúde bem estruturado. Os incentivos para a estruturação a longo prazo do sistema de saúde local deveriam parecer aos gestores municipais mais atraentes do que o pagamento pelo governo federal de bolsas para os profissionais temporários do PMMB. 
Um componente fundamental de uma política de estruturação de sistemas de saúde para áreas rurais e remotas é a formaçấo de recursos humanos capacitados para atuarem nessas regióes. Isso envolve a reorganização dos currículos médicos e a descentralização da formação em saúde, juntamente com medidas para facilitar o acesso de estudantes do interior aos cursos de medicina. ${ }^{7} \mathrm{O}$ padrão-ouro para a formaçâo pós-graduada de médicos para a atençâo primária de áreas rurais e remotas é o treinamento em programas de residência em Medicina de Família e Comunidade, que os capacita para serem resolutivos no manejo dos problemas mais frequentes vistos nos territórios em que atuam, inclusive nas regiōes rurais, bem como para prestarem cuidado continuado às populações que habitam nesses territórios.

Para debater esses e outros importantes assuntos ligados à saúde das populaçôes rurais, foi realizada este ano, em Gramado, a 12a Conferência Mundial de Saúde Rural, que reuniu mais de 700 participantes de mais de 20 países, incluindo autoridades mundiais nesse tema. Durante a conferência, foi elaborada a Declaração de Gramado, que está sendo publicada neste número da Revista Brasileira de Medicina de Família e Comunidade9, e que propóe recomendaçôes sobre como melhorar a saúde rural por meio da organizaçáo de sistemas de saúde e sobre como estruturar políticas de recursos humanos para atuarem nesses sistemas. Essas recomendaçóes, se incorporadas no desenho das políticas para provimento e fixação de médicos no Brasil, têm grande potencial de contribuir para superar a defasagem rural-urbana e propiciar cuidados de saúde de qualidade para a população que mora em áreas rurais e remotas.

\section{Referências}

1. Conselho Federal de Medicina (CFM); Conselho Regional de Medicina do Estado de São Paulo (CREMESP). Demografia Médica no Brasil: cenários e indicadores de distribuição. São Paulo: CFM; CREMESP; 2013 [acesso em: 2014 Sep 02]. Disponível em: http://www.cremesp.org.br/pdfs/DemografiaMedicaBrasilVol2.pdf.

2. Garcia B, Rosa L, Tavares F. Projeto mais médicos para o Brasil: apresentação do programa e evidências acerca de seu sucesso. Informações FIPE. Mar 2014 [acesso em 2014 Sep 02];402:26-36. Disponível em: http://www.fipe.org.br/publicacoes/downloads/bif/2014/3_26-36-bea-etal.pdf.

3. Conselho Regional de Medicina do Estado de São Paulo (CREMESP). Médicos cubanos: CFM considera a imigração anunciada pelo Ministério da Saúde como medida eleitoreira e irresponsável [Internet]. 2013 Aug 26 [acesso em 2014 Sep 02]. Disponível em: http://www.cremesp.org.br/?siteAcao=NoticiasC\&id=2988.

4. Governo diz que Mais Médicos supera meta de cobertura no país [Internet]. G1. 2014 Jun 30 [acesso em 2014 Sep 02]. Disponível em: http://g1.globo.com/ciencia-e-saude/noticia/2014/06/governo-diz-que-mais-medicos-supera-meta-de-cobertura-no-pais.html.

5. Brasil. Lei n 12.871, de 22 de outubro de 2013. Institui o Programa Mais Médicos, altera as Leis no 8.745, de 9 de dezembro de 1993, e nº 6.932, de 7 de julho de 1981, e dá outras providências. Diário Oficial da União. 2013 Oct 23 [acesso em 2014 Sep 02]. Disponível em: http://www.planalto.gov.br/ccivil_03/_Ato2011-2014/2013/Lei/L12871.htm.

6. Alagoas Real [blog on the Internet]. Mais Médicos continua causando demissão no interior de Alagoas. 2013 Sep 20 [acesso em 2014 Sep 02]. Disponível em: http://alagoasreal.blogspot.com.br/2013/09/mais.medicos.continua.causando.demissao.de.profissionais.no.interior.de.alagoas.html.

7. World Health Organization (WHO). Increasing access to health workers in remote and rural areas through improved retention. Geneva; 2010.

8. Starfield B. Primary care: balancing health needs, services and technologies. New York: Oxford University Press; 1998.

9. Targa LV, Wynn-Jones J, Howe A, Anderson MIP, Lopes JMC, Lermen Jr N, et al. Declaração de Gramado pela Saúde Rural nos países em desenvolvimento. Rev Bras Med Fam Comunidade. 2014;9(32):pp-pp. Disponível em http://dx.doi.org/10.5712/rbmfc9(31)982. 